\title{
Inter-professional and inter-departmental alcoholism rehabilitation program
}

\author{
Masahiro Kikuchi', Naomi Matsutani', Ryota Ishihara ${ }^{2}$, Masako Sugihara², Yuuki Mizuno ${ }^{3}$, Chiyo Chiba ${ }^{2}$, \\ Takahiro Ohta ${ }^{4}$, Eri Yamada ${ }^{5}$, Sota Oguro ${ }^{6}$, Yasuko Sato ${ }^{7}$, Hiroki Bessho ${ }^{8}$, and Yoshinori Horie ${ }^{9}$ \\ Departments of ${ }^{1}$ Gastroenterology, ${ }^{2}$ Psychiatry, ${ }^{3}$ Medical Welfare, ${ }^{4}$ Pharmacy, ${ }^{5}$ Nutrition, ${ }^{6}$ Radiology, ${ }^{7}$ Nursing, and ${ }^{8}$ Dentistry, National \\ Hospital Organization Tokyo Medical Center, Tokyo; ${ }^{9}$ Department of Gastroenterology, Shonan Keiiku Hospital, Kanagawa, Japan
}

\begin{abstract}
A 3-month alcoholism rehabilitation program at psychiatric hospitals is common in Japan for patients with alcohol use disorder (AUD). However, many AUD patients are often hospitalized for the treatment of digestive disorders due to alcohol-related liver diseases and pancreatitis. In this sense, AUD patients need to be better supported by professionals and departments in general hospitals. Here we analyzed the problems in alcohol-related medical care in Japan and examined the measures to be taken at general hospitals. (Clin Mol Hepatol 2020;26:626-632)
\end{abstract}

Keywords: Alcoholic liver disease; Alcohol related disorder; Rehabilitation

\section{INTRODUCTION}

Alcohol use disorder (AUD) is a major contributor to the global burden of chronic liver disease.' In Europe, alcohol-related liver disease (ALD) is the most common cause of chronic liver disease, and it accounts for over $75 \%$ of cases with cirrhosis. ${ }^{2,3}$ The percapita alcohol consumption in South Korea is now considered to be among the highest in the world. ${ }^{4}$ Economic loss due to alcoholrelated diseases and accidents has increased with the increase in alcohol consumption. ${ }^{5}$

In recent years, the prevalence of alcoholic cirrhosis compared to that of non-alcoholic types has been increasing in Japan. The result of a national survey by Horie et al. ${ }^{6}$ showed that $30.6 \%$ cases of liver cirrhosis were alcohol-related in 2012, while the incidence was only $19.9 \%$ in 2007-2008. In addition, it has been reported that $25.8 \%$ of hepatocellular carcinoma cases are related to alcohol. ${ }^{7}$ Furthermore, there are many hepatocellular carcinomas resulting from diabetic complications, and in males, and elderly patients with alcoholic liver cirrhosis. ${ }^{8}$ Recently, as hepatitis $\mathrm{C}$ is starting to be eradicated by direct-acting antiviral drugs, addressing the problem of alcohol is the current priority.

In Japan, the "Basic Law on Alcohol Health Disorder Measures" came into effect in June 2014, addressing the issue as to how the core general hospitals can function and be involved, including regional cooperation. The most important issue was to strengthen the cooperation between internal medicine and psychiatry. In fact, when comparing the group that treats alcohol-related physical illnesses and mental care together in one clinic to those who are treated in two different clinics (physical clinic and mental clinic), the former showed better results for abstinence and mortality rates after 2 years. ${ }^{9}$ In Europe and the United States, it is thought that the total care provided under one medical system from physi-

\section{Abbreviations:}

ALD, alcohol-related liver disease; ARP, alcoholism rehabilitation program; AUD, alcohol use disorder; CBT, cognitive behavioral therapy; MET, motivational enhancement therapy; MI, motivational interviewing

\section{Corresponding author : Masahiro Kikuchi}

Department of Gastroenterology, National Hospital Organization Tokyo Medical Center, 2-5-1 Higashigaoka, Meguro-ku, Tokyo 152-8902, Japan Tel: +81-3-3411-0111, Fax: +81-3-3411-2596

E-mail:kikuchim490611@yahoo.co.jp

https://orcid.org/0000-0002-7200-1796 
cal illness to mental illness of alcohol will improve the prognosis of AUD patients. ${ }^{10,11}$

When launching the alcoholic medical system, some problems were identified. Previously, psychiatrists did not have an abstinence program; hence, there were few cases where psychiatry was used to treat alcoholism, and gastrointestinal symptoms such as hepatitis, pancreatitis, and gastric ulcer caused by alcohol were at the forefront. In many cases, patients were hospitalized in the Department of Gastroenterology and were discharged immediately after the completion of medical treatment. Patients often had one-way medical treatment saying that they were not qualified to go to the hospital if they could not stop drinking. In many cases, these patients resumed drinking and returned to the emergency department, and our hospital data showed an inpatient repeat rate of $27 \%$. $^{12}$

This medical intervention is ineffective for the care of the patient and the family, and also medically and economically inefficient. The most critical issue here is how to create an environment in which alcohol can be withdrawn after medical treatment for internal diseases.

Why is the repeat rate of alcohol patients with alcohol-related problems so high? There are various factors that should be considered when answering this question. First, there is a problem with the medical system. In Japan, for an estimated 1.09 million patients, there are only 229 medical institutions nationwide. It is assumed that many institutions refrain from returning to alcohol therapy since AUD patients are shunned and unilaterally prohibited from drinking. On the other hand, many AUD patients, especially those with mild symptoms, often resist medical treatment for the purpose of treating alcohol abuse. ${ }^{13}$

The untreated rate of patients with AUD around the world is $78 \%,{ }^{14}$ which is more serious compared to the current situation in Japan, where only 50,000 out of the estimated 1.09 million patients (95\% untreated rate) are not connected to a specialized treatment institution. ${ }^{15}$ Alcohol-related disorders are not properly understood, since physicians in first-aid emergency and primary care often overlook AUD patients. ${ }^{16}$ At the primary care unit, it is reported that the proportion of AUD patients with alcohol-related problems is $12.6 \%$ among men. ${ }^{17}$ Alcohol-related disorder needs to be treated as a common disease. Primary care physicians should be actively suspicious of alcohol use when examining patients with conditions such as unexplained cardiac hypertrophy and arrhythmia, bilateral femoral neck fractures without steroids or collagen disease, macrocytic anemia not seen in blood diseases, and high protein induced by vitamin $\mathrm{K}$ absence or antagonist II level without cancers. It is important to improve the diagnostic skills of primary care physicians so that they can associate alcohol with physical disorders caused by alcohol.

Based on this background, we considered it important to understand the current state of medical practice for AUD patients, and conducted a questionnaire survey of young doctors and nurses (Fig. 1). ${ }^{18}$ This led to the following: 1) insufficient interviews re-

\section{Survey of actual conditions for alcoholic treatment}

Do you know the adequate volume of alcohol consumption?

Do you know how to calculate the cumulative drinking amount?

Are you aware of the CAGE* questionnaire (alcoholism screening test) and its contents?

Do you know how to deal with alcohol withdrawal symptoms?

Do you conduct a proper interview regarding alcohol consumption?

Do you drink alcohol yourself?

Is there a trauma that makes alcoholic patients shy away?

Have you ever had a problem with alcohol treatment?

Yes

Medical pathology or patient's social background?

\begin{tabular}{cc}
\hline $\begin{array}{c}\text { Young doctor } \\
\text { Yes: } 71 \%\end{array}$ & Nurse \\
Yes: $29 \%$ & Yes: $20 \%$ \\
Yes: $82 \%$ & Yes: $0 \%$ \\
& Yes: $13 \%$ \\
Yes: $88 \%$ & Yes: $60 \%$ \\
Yes: $65 \%$ & Yes: $40 \%$ \\
Yes: $100 \%$ & Yes: $87 \%$ \\
Yes: $47 \%$ & Yes: $47 \%$ \\
Yes: $65 \%$ & Yes: $53 \%$ \\
Medical pathology: $21 \%$ & Medical pathology: $25 \%$ \\
Patient social background: $79 \%$ & Patient social background: $75 \%$
\end{tabular}

Figure 1. Survey of actual conditions for alcoholic treatment, conducted among young doctors and nurses. To understand the current state of the medical field for alcohol use disorder patients in our hospital, we conducted a questionnaire among young doctors and nurses. Results for nine questions are shown. *Asks the following: Have you ever felt you needed to cut down on your drinking? / Have people annoyed you by criticising your drinking? / Have you ever felt guilty about drinking? / Have you ever felt you needed a drink first thing in the morning (eye-opener) to steady your nerves or to get rid of a hangover? 
garding alcohol consumption were conducted, even by resident doctors; 2) there were many cases where patients were treated without understanding the management of withdrawal symptoms and the alcoholism screening test (CAGE questionnaire); and 3) medical staffs tended to keep AUD patients away due to past trauma, which indicated that a change in stereotypes related to alcoholism treatment was essential. As a solution to this, alcoholrelated problems were often taken up in a liver disease class where awareness activities centered on the life guidance for patients were conducted. In addition to the patients, their families, staff, and co-medical staffs also participated in the class, and shared successful cases.

The concept of harm reduction has been advocated in order to raise awareness of alcoholism on the part of medical staff and to reduce the gap in patients who are resistant to treatment for the purpose of abstinence. Harm reduction is a concept which states that if drinking cannot be stopped immediately, one should begin by reducing the amount of drinking; and therefore, the harm caused by drinking is reduced as much as possible, and consensus has been gained worldwide in recent years. ${ }^{19,20}$

Medication interventions have limited options, especially for AUD with liver disease. Although disulfiram, naltrexone, and acamprosate have been found to be effective in managing $A U D_{1}{ }^{21}$ there is a paucity of data regarding their safety in the treatment of AUD with liver disease. Only baclofen has been shown to be safe and effective in patients with chronic hepatitis and AUD, and is approved for use in patients in the United States. ${ }^{22,23}$

Despite evidence showing that outcomes improve with integra- tion of psychosocial and medical care, ${ }^{24}$ there have been few studies on behavioral and/or pharmacological treatments in AUD with liver disease. Alcohol abstinence is the most important therapeutic goal, as abstinence can improve the outcome at all stages of liver disease. ${ }^{25-27}$

Specific psychosocial and behavioral therapies for AUD include cognitive behavioral therapy (CBT) and motivational enhancement therapy (MET). CBT focuses on identifying triggers and maladaptive behaviors that engender relapse. This approach encourages coping mechanisms to allow replacement of alcohol-laden with alcohol-free circumstances. ${ }^{28}$ MET seeks to frame the decision to stop or modify drinking in terms of a dilemma, and helps the patient to work through the dilemma by "rolling with the resistance" to change. ${ }^{29}$

We found four studies (one randomized controlled trial and three observational studies) that evaluated an integrated approach and reported a similar magnitude of effects (alcohol abstinence rate 36-74\%) (Table 1). ${ }^{9,30-32}$ These studies examined a range of psychotherapies (combination therapies which included combinations of CBT and MET or CBT, MET, and motivational interviewing [MI]). While psychosocial interventions alone were not effective in maintaining abstinence, ${ }^{33}$ combining comprehensive medical care and behavioral approaches, such as CBT and MET, did increase abstinence rates. ${ }^{24}$ This indicates that the use of integrated care to treat AUD with liver disease may lead to better outcomes.

Table 1. Alcohol psychotherapies for ARLD in RCT and non-RCTs

\begin{tabular}{|c|c|c|c|c|c|c|}
\hline Study & $\mathrm{N}$ & Liver disease & $\begin{array}{l}\text { Intervention } \\
\text { elements }\end{array}$ & $\begin{array}{c}\text { Treatment duration } \\
\text { (months) }\end{array}$ & $\begin{array}{c}\text { Alcohol } \\
\text { abstinence (\%) }\end{array}$ & $P$-value \\
\hline \multicolumn{7}{|l|}{ RCT } \\
\hline \multirow[t]{2}{*}{$\begin{array}{l}\text { Willenbring and } \\
\text { Olson }^{9} \text { (1999) }\end{array}$} & $\begin{array}{l}\text { Intervention, } \\
29\end{array}$ & ARLD & CBT \& MET & 24 & 74 & 0.02 \\
\hline & Control, 32 & ARLD & General care & NR & 48 & 0.02 \\
\hline \multicolumn{7}{|l|}{ Non-RCT } \\
\hline $\begin{array}{l}\text { Addolorato et al. } \\
\text { (2013) }\end{array}$ & 55 & $\begin{array}{l}\text { ARLD with/without } \\
\text { HCV, HBV }\end{array}$ & Integrated CBT & $N R$ & 67.3 & 0.03 \\
\hline $\begin{array}{l}\text { Proeschold-Bell et al. }{ }^{31} \\
(2012)\end{array}$ & 53 & ARLD with HCV & $\begin{array}{l}\text { Integrated CBT \& } \\
\text { MET }\end{array}$ & 6 & 44 & $<0.01$ \\
\hline $\begin{array}{l}\text { Dieperink et al. }{ }^{32} \\
(2010)\end{array}$ & 47 & ARLD with HCV & $\begin{array}{l}\text { Integrated CBT, } \\
\text { MET, \& MI }\end{array}$ & 6 & 36 & NR \\
\hline
\end{tabular}

ARLD, alcohol-related liver disease; RCT, randomized controlled trial; HCV, hepatitis C virus; HBV, hepatitis B virus; CBT, cognitive behavioral therapy; MET, motivational enhancement therapy; MI, motivational interviewing; NR, not reported. 


\section{DISCUSSION}

\section{Problems in alcohol treatment in Japan}

A matter of concern is shown in the results of the questionnaire, where there is prejudice or little understanding about alcohol medical care, and the current situation is that medical care is not adequate (Fig. 1). In Japan, the "Diagnostic and Treatment Guidelines for New Alcohol/Drug Use Disorders" was established in 2018, and it is a major premise of alcohol medical treatment that medical treatment can be conducted without selecting patients. ${ }^{34}$ On the other hand, in the actual medical field, the attitude towards alcoholic medicine is insufficient in doctors, young medical doctors, and co-medicals. There are several possible causes for this. First, alcoholism may not be considered a disease due to withdrawal delirium, patient abuse, and violence. It is important to support this as a medical team treatment including psychiatry and not individually. Second, there is an insufficient understanding of the background factors. Without understanding the causes of drinking, the living environment, and the relationship with fam- ily and society, one cannot attain prohibition. Patients with AUD often lose their jobs and families, are isolated from society, and depend on alcohol. Intervention in the early stages of physical treatment by social workers and nurses is also effective in preparing for subsequent mental care and strengthening the system after discharge. Third, there is often a lack of medical history regarding alcohol consumption such as information on previous drinking behavior, cumulative drinking amount, types of alcohol consumed and the amount, as well as frequency of alcohol consumption (average drinking days). Grasping the concept of alcohol consumption is a complicated task, but is essential for understanding alcohol-related organ damage. AUD tends to be underreported and needs to spotted. Finally, in accepting such difficult cases, it is important not to leave it to the AUD treatment team but to accept it as a common disease throughout the hospital.

\section{Strategies that should be addressed in general hospitals for alcohol treatment}

There is a 4-year follow-up study that relates to the survival rate

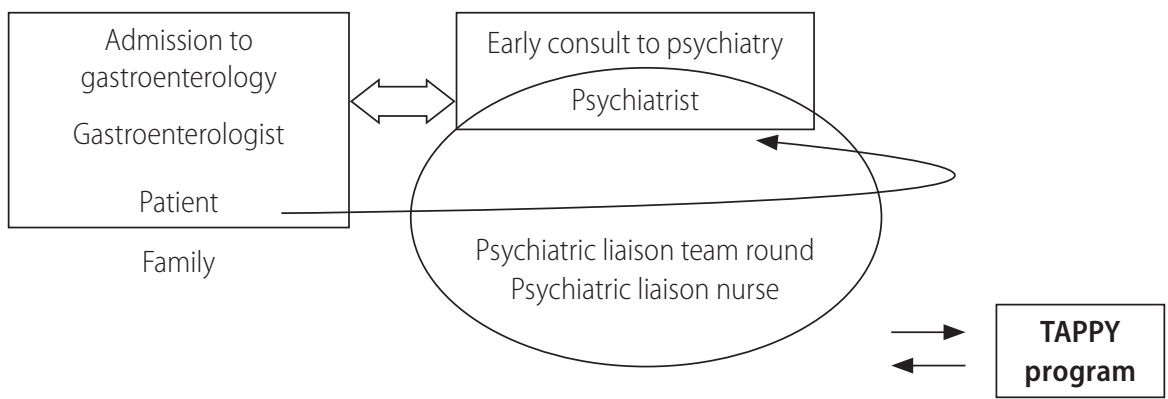

Psychiatric social worker

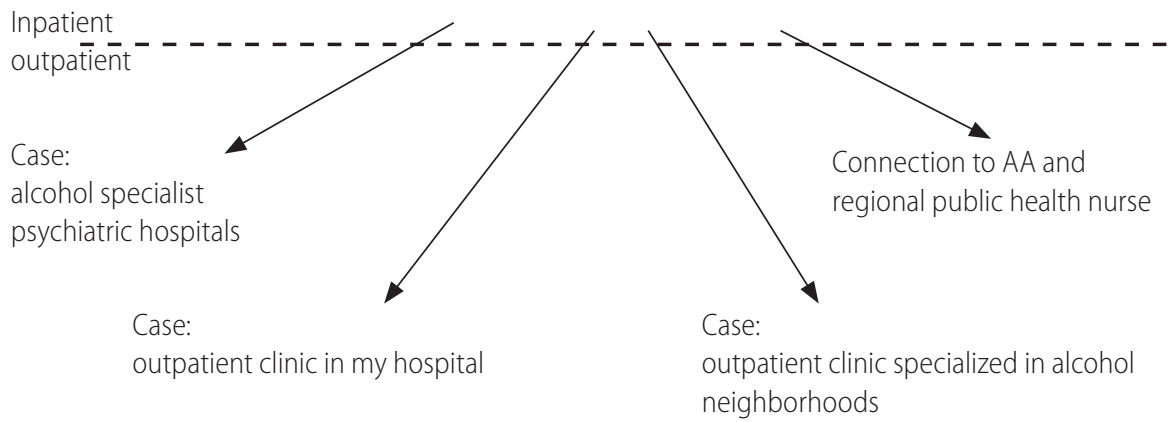

Figure 2. Alcohol treatment model, including ARP. At the early stage of hospitalization for internal medicine, a psychiatrist was consulted, and physical treatment and mental care intervention were provided. The psychiatric liaison team makes daily round visits, and a report is then shared at the conference. When the treatment course at the internal medicine department is completed, the patient will be transferred to a psychiatry department, and a short-term alcohol hospitalization treatment program (TAPPY) will be conducted. After examining each case from the time of admission, the social worker plays a central role in determining the follow-up system for discharge. TAPPY, Tokyo Medical Center Alcoholic Program with Physicians; AA, alcoholics anonymous; ARP, alcoholism rehabilitation program. 
of AUD patients and whether they can withdraw from alcohol consumption after being discharged from the alcoholism rehabilitation program (ARP), ${ }_{1}^{35}$ but no studies with high level of evidence have been conducted thereafter. At the turning point in the treatment of alcoholism in Japan, the rate of abstinence from 1 to 3 years after treatment ranges from $7 \%$ to $30 \%$, while conversely, the mortality rate is remarkably high. ${ }^{36}$

In Japan, ARP treatment for AUD is currently performed primarily at psychiatric unit hospitals. However, it has a wide range of effects not only on the brain and mental state, but also on the digestive, endocrine, and circulatory bodies, as well as family, society, and secondary psychological symptoms. In this sense, it is rather significant that general hospitals carry out ARP for occupations involving multiple clinical departments.

Figure 2 shows our alcohol rehabilitation model. ${ }^{12}$ With the simultaneous intervention of a psychiatrist at an early stage, interviews regarding the patient's background, family relationships, and motivations for drinking were conducted in detail, and mental care was performed in parallel with medical treatment. A psychiatric liaison team made a daily round visit to provide team medical care. Important information was shared through conferences. The team consulted with one another after examining each case. The patient then decided whether to participate in ARP. The main requirements for ARP were the patient's willingness to participate, completion of physical treatment, and hospitalization in the psychiatric ward. A workshop was held in a psychiatric ward within a short period of 2 weeks, and daily lecture and discussion workshop were conducted by multi-professionals.

Several effects have been produced by ARP, which combines comprehensive medical care and a behavioral approach with team medical treatment. First, in the case where patients were discharged from the hospital when the treatment of physical illness had been completed, ARP made it possible for most patients to be connected to an environment where they can continue their alcoholism treatment. This reduced the number of repeaters who revisited the emergency department due to alcohol consumption. By taking advantage of the knowledge on patient's background and repeatedly consulting with the team, it is possible to create a suitable environment for the patient to continue alcohol treatment. It is also a good idea to intervene early during physical therapy, as timing is an important factor for motivating patients to give up drinking.

As a team, this interaction allows sharing of various opinions and acknowledgement of each member; as a result, it will be the driving force to tackle the difficult problems associated with alco- hol treatment.

As a limitation, severe cases are difficult to manage with ARP, and these cases have been transferred to alcohol specialist psychiatric hospitals.

\section{CONCLUSIONS}

A general hospital and a short-term hospitalized ARP provided a new opportunity for patients with AUD who had not been treated until now, and became an effective means to intervene before the condition becomes severe. Being involved in other professions, as well as having a full understanding and accepting alcohol dependence, may be important steps toward recovery.

\section{Authors' contribution}

Kikuchi M., Matsutani N., Ishihara R., Sugihara M., Mizuno Y.

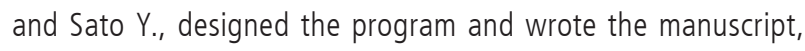
Chiba C.,Ohta T.,Yamada E., Oguro S. and Bessho H., performed the program, Horie $Y$. reviewed and refined the manuscript.

\section{Acknowledgements}

The authors would like to thank psychiatrists of Kurihama Medical and Addiction Center.

\section{Conflicts of Interest}

The authors have no conflicts to disclose.

\section{REFERENCES}

1. Rehm J, Samokhvalov AV, Shield KD. Global burden of alcoholic liver diseases. J Hepatol 2013;59:160-168.

2. Blachier M, Leleu H, Peck-Radosavljevic M, Valla DC, Roudot-Thoraval F. The burden of liver disease in Europe: a review of available epidemiological data. J Hepatol 2013;58:593-608.

3. Shield KD, Rehm J, Gmel G, Rehm MX, Allamani A. Alcohol consumption, alcohol dependence, and related mortality in Italy in 2004: effects of treatment-based interventions on alcohol dependence. Subst Abuse Treat Prev Policy 2013;8:21.

4. Jang JY, Kim DJ. Epidemiology of alcoholic liver disease in Korea. Clin Mol Hepatol 2018;24:93-99.

5. Korean Association for the Study of the Liver (KASL). KASL clinical practice guidelines: management of alcoholic liver disease. Clin Mol Hepatol 2013;19:216-254.

6. Horie Y, Ebinuma H, Kikuchi M, Nakamoto N, Kanai T. Current status 
of alcoholic liver diseases in Japan. Kanzo 2015;56:366-368.

7. Horie Y, Kikuchi M, Ebinuma H, Shiba S, Taniki N, Chu PS, et al. Current status of alcoholic hepatocellular carcinoma in Japan-nationwide survey in 2014. Kanzo 2016;57:538-547.

8. Kikuchi M, Horie Y, Ebinuma H, Taniki N, Nakamoto N, Kanai T. Alcoholic liver cirrhosis and significant risk factors for the development of alcohol-related hepatocellular carcinoma--Japan, 2012. Nihon Arukoru Yakubutsu Igakkai Zasshi 2015;50:222-234.

9. Willenbring ML, Olson DH. A randomized trial of integrated outpatient treatment for medically ill alcoholic men. Arch Intern Med 1999;159:1946-1952.

10. Ostergaard M, Jatzkowski L, Seitz R, Speidel S, Weber T, Lübke N, et al. Integrated treatment at the first stage: increasing motivation for alcohol patients with comorbid disorders during inpatient detoxification. Alcohol Alcohol 2018;53:719-727.

11. Saitz R, Cheng DM, Winter M, Kim TW, Meli SM, Allensworth-Davies $D$, et al. Chronic care management for dependence on alcohol and other drugs: the AHEAD randomized trial. JAMA 2013;310:11561167.

12. Kikuchi M, Sugihara M, Ishihara R, Oguro S, Sato Y, Mizuno Y, et al. Interdisciplinary approach (TAPPY: Tokyo Medical Center alcoholic program with physicians) for alcohol use disorders and alcoholism. Alcohol and Biomedical Research 2019;38:52-53.

13. Saunders SM, Zygowicz KM, D'Angelo BR. Person-related and treatment-related barriers to alcohol treatment. J Subst Abuse Treat 2006;30:261-270.

14. Kohn R, Sexena S, Levav I, Saraceno B. The treatment gap in mental health care. Bull World Health Organ 2004;82:858-866.

15. Higuchi S. Comprehensive research on measures against harmful use of alcohol based on WHO global strategy. National Institute of Public Health web site, <https://mhlw-grants.niph.go.jp/niph/search/ NIDD00.do? resrchNum=201315050A >. Accessed 30 Jun 2020.

16. Kitamura K, Fetters MD, Takenaka H, Sato J, Ban N. Recognition of alcohol-related problems by primary care physicians in Japan. Jpn J Prim Care 2001;24:104-110.

17. Ban S, Kitamura K, Ichihara S, Yanagida K, Fukuoka H, Tasaka Y, et al. Primary care multicenter collaborative study on alcohol-related disorders. Japan Medical Journal 1999;3945:37-43.

18. Kikuchi M, Mizuno Y, Sato Y, Sugihara M, Horie Y. Problems in alcohol medical care and efforts at my hospital. HEP 2017;44:677-682.

19. National Institute for Health and Care Excellence (NICE). Alcoholuse disorders: diagnosis, assessment and management of harmful drinking and alcohol dependence. London: NICE, 2011.

20. Rolland B, Paille F, Gillet C, Rigaud A, Moirand R, Dano C, et al. Pharmacotherapy for alcohol dependence: the 2015 recommendations of the French Alcohol Society, issued in partnership with the european federation of addiction societies. CNS Neurosci Ther 2016;22:25-37.
21. Vuittonet $\mathrm{CL}$, Halse $\mathrm{M}$, Leggio $\mathrm{L}$, et al. Pharmacotherapy for alcoholic patients with alcoholic liver disease. Am J Health-Syst Pharm 2014;71:1265-1276.

22. Addolorato G, Leggio L, Ferrulli A, Cardone S, Vonghia L, Mirijello $A$, et al. Effectiveness and safety of baclofen for maintenance of alcohol abstinence in alcohol-dependent patients with liver cirrhosis: randomised, double-blind controlled study. Lancet 2007;370:19151922.

23. Leggio L, Ferrulli A, Zambon A, Caputo F, Kenna GA, Swift RM, et al. Baclofen promotes alcohol abstinence in alcohol dependent cirrhotic patients with hepatitis $\mathrm{C}$ virus ( $\mathrm{HCV}$ ) infection. Addict Behav 2012;37:561-564.

24. Khan A, Tansel A, White DL, Kayani WT, Bano S, Lindsay J, et al. Efficacy of psychosocial interventions in inducing and maintaining alcohol abstinence in patients with chronic liver disease: a systematic review. Clin Gastroenterol Hepatol 2016;14:191-202.e1-e4; quiz e20.

25. Borowsky SA, Strome S, Lott E. Continued heavy drinking and survival in alcoholic cirrhotics. Gastroenterology 1981;80:1405-1409.

26. Brunt PW, Kew MC, Scheuer PJ, Sherlock S. Studies in alcoholic liver disease in Britain. I. Clinical and pathological patterns related to natural history. Gut 1974;15:52-58.

27. Luca A, García-Pagán JC, Bosch J, Feu F, Caballería J, Groszmann RJ, et al. Effects of ethanol consumption on hepatic hemodynamics in patients with alcoholic cirrhosis. Gastroenterology 1997;112:12841289.

28. Larimer ME, Palmer RS, Marlatt GA. Relapse prevention. An overview of Marlatt's cognitive-behavioral model. Alcohol Res Health 1999;23:151-160.

29. Miller WR, Benefield RG, Tonigan JS. Enhancing motivation for change in problem drinking: a controlled comparison of two therapist styles. J Consult Clin Psychol 1993;61:455-461.

30. Addolorato G, Mirijello A, Leggio L, Ferrulli A, D'Angelo C, Vassallo $G$, et al. Liver transplantation in alcoholic patients: impact of an alcohol addiction unit within a liver transplant center. Alcohol Clin Exp Res 2013;37:1601-1608.

31. Proeschold-Bell RJ, Patkar AA, Naggie S, Coward L, Mannelli P, Yao J, et al. An integrated alcohol abuse and medical treatment model for patients with hepatitis C. Dig Dis Sci 2012;57:1083-1091.

32. Dieperink E, Ho SB, Heit S, Durfee JM, Thuras P, Willenbring ML. Significant reductions in drinking following brief alcohol treatment provided in a hepatitis C clinic. Psychosomatics 2010;51:149-156.

33. Weinrieb RM, Van Horn DH, Lynch KG, Lucey MR. A randomized, controlled study of treatment for alcohol dependence in patients awaiting liver transplantation. Liver Transpl 2011;17:539-547.

34. Naruse N. Skills required of supporters. In: Higuchi S, ed. New guidelines for diagnosis and treatment of alcohol/drug use disorders. Tokyo: Shinko Igaku Shupan, 2018:34. 


\section{CLINCAL And MOLECULAR
HEPATOLOGY}

Volume_26 Number_4 October 2020

35. Yokoyama K, Ishii H. Relationship between prognosis of alcoholism and complication of diabetes. Igakunoayumi 1991;156:681.

36. Higuchi S, Saito T. Reduction in alcohol consumption: therapeutic goal in alcohol dependence treatment. Nihon Arukoru Yakubutsu Igakkai Zasshi 2013;48:17-31. 